\title{
Identification and characterization of Pannexin expression in the mammalian cochlea
}

\author{
Xiao-Hui Wang, Michele Streeter, Ying-Peng Liu, and Hong-Bo Zhao \\ Department of Surgery - Otolaryngology, University of Kentucky Medical Center, 800 Rose \\ Street, Lexington, KY 40536
}

\begin{abstract}
The gap junction in vertebrates is encoded by the connexin gene family. Recently, a new gene family termed pannexin (Panx) has been identified in vertebrates and found to encode gap junctional proteins as well. To date, three pannexin isoforms (Panx1, 2 and 3) have been cloned from mouse and human genomes. In this study, expression of pannexins in the mouse and rat cochlea was investigated. PCR and Western blot analysis showed that all three pannexin isoforms were expressed in the cochlea. Immunofluorescent staining showed that Panx 1 expression was extensive. In the organ of Corti, Panx1 labeling was found in supporting cells, including pillar cells, Hensen cells, Claudius cells and Boettcher cells. Both surface plaque-like punctate labeling and diffuse-cytoplasmic labeling were visible. However, the labeling was weak and rare in Deiters cells. No labeling was found in the hair cells. Intense labeling for Panx1 was also observed in the interdental cells in the spiral limbus, the inner and outer sulcus cells, and the type II fibrocytes in the spiral prominence and central region in the cochlear lateral wall. However, no overlapping labeling was observed. In addition, Panx1 labeling was detectable in the Reissner's membrane and strial blood vessel cells. Panx2 labeling was restricted to the basal cells in the stria vascularis and was also detectable in the spiral ganglion neurons. However, no overlapping labeling for Panx 1 and Panx2 was observed. Finally, Panx3 labeling was exclusively observed in the cochlear bone. Thus, Panx 1, 2 and 3 are abundantly expressed in the mammalian cochlea and demonstrate distinct cellular distributions. Like connexins, they may play an important role in hearing.
\end{abstract}

\section{Keywords}

Gap junction; hemichannel; cochlea; connexin; intercellular communication; deafness

\section{Introduction}

Gap junction is an intercellular channel that exists extensively in both vertebrates and invertebrates. A gap junctional channel is formed by two hemichannels; each hemichannel is composed of six subunits (Harris, 2001). The gap junctional proteins in vertebrates are encoded by the connexin gene family, which contains more than 20 connexin isoforms in mammals (Willecke et al., 2002), whereas the gap junctional proteins in invertebrates are encoded by an unrelated innexin gene family. Recently, by application of genoinformatics, innexin homologues have been found in human and mouse genomes (Panchin et al., 2000; Bruzzone et al., 2003; Baranova et al., 2004) and also encode gap junctional proteins in

\section{Correspondence to: Hong-Bo Zhao.}

Corresponding author: Hong-Bo Zhao, Ph.D./M.D. Associate Professor Dept. of Surgery - Otolaryngology University of Kentucky Medical Center 800 Rose Street Lexington, KY 40536 - 0293 Tel: 859-257-5097 x 82138 Fax: 859-257-5096 E-mail:

hzhao2@uky.edu. 
vertebrates (Shestopalov and Panchin, 2008). These homologues are termed pannexins. So far, three pannexin isoforms (Panx1, 2, and 3) have been cloned (Bruzzone et al., 2003; Baranova et al., 2004).

Despite the lack of similar sequences with connexins, the results from the protein structure analysis have shown that pannexin proteins share many similarities at the structural and functional levels (Shestopalov and Panchin, 2008). Both connexin and pannexin proteins possess four transmembrane domains, two extracellular loops, one intracellular loop, and intracellular $\mathrm{N}$ - and C-termini (Baranova et al., 2004). The pannexin proteins can also assemble hemichannels and intercellular gap junctional channels, which possess voltage and chemical gating (Bruzzone et al., 2003, 2005; Bao et al., 2004). They are permeable to ions and small molecules such as ATP (Bao et al., 2004; Locovei et al., 2006a, 2006b; Vanden Abeele et al., 2006; Huang YJ et al., 2007; Lai et al., 2007; Pelegrin and Surprenant, 2007; Peters et al., 2007).

Pannexins have ubiquitous expression. In rodents, pannexin expression has been found in many tissues, including the brain, spinal cord, eye, olfactory bulb, thyroid, prostate, and kidney (Bruzzone et al., 2003; Baranova et al., 2004; Vogt et al., 2005; Ray et al., 2005, 2006; Dvoriantchikova et al., 2006a, 2006b; Zappala et al., 2006). In humans, high levels of Panx 1 expression have been found in the heart, gonads, and skeletal muscles (Baranova et al., 2004). There is a well-established distinct distribution pattern of Panx 1 expression in the central nervous system (Ray et al., 2005, 2006; Weickert et al., 2005; Zappala et al., 2006; Zoidl et al., 2007). Panx2 seems to be largely distributed in the brain, and can be colocalized with Panx1 (Bruzzone et al., 2003; Baranova et al., 2004; Vogt et al., 2005; Ray et al., 2006; Zappala et al., 2007). Panx2 expression is also detected in the eye and testicular tissues (Baranova et al., 2004; Dvoriantchikova et al., 2006a, 2006b). Panx3 is predominantly expressed in the skin and cartilage and also detected in the lung, liver, kidney, spleen, and brain (Baranova et al., 2004; Penuela et al., 2007). However, it remains unclear whether pannexins are expressed in the cochlea.

There are abundant gap junctions in the cochlea (Kikuchi et al., 1995; Forge et al., 1999, 2003; Zhao and Yu, 2006; Liu and Zhao, 2008). Two independent gap junctional networks have been identified: the epithelial gap junctional network between supporting cells in the auditory sensory epithelium in the organ of Corti and the connective tissue gap junctional network between the connective tissue cells in the cochlear lateral wall (Kikuchi et al., 1995; Zhao et al., 2006). However, there is no gap junctional coupling between hair cells or between hair cells and supporting cells (Zhao and Santos-Sacchi, 1999, 2000; Zhao, 2000, 2003). It has been found that connexin mutations can induce hearing loss (Kelsell et al., 1997; Zhao et al., 2006), indicating that gap junction-mediated intercellular communication plays an important role in hearing. The putative contribution of pannexins in intercellular communications prompted us to examine pannexin expression in the cochlea. In this study, we demonstrate for the first time that Panx1, Panx2, and Panx3 are present in the mammalian cochlea with distinct distribution patterns, indicating that they may play diverse functions in the inner ear.

Preliminary data of this work have been presented at a meeting in abstract form (Wang et al., 2008).

\section{Materials and Methods}

\section{Animal and cochlear tissue preparations and cochlear section cutting}

A total of 20 adult C57/BL6 mice and 15 adult rats were used. The animal preparation has been described elsewhere (Zhao and Yu 2006; Yu et al., 2006; Liu and Zhao, 2008). Briefly, 
animals were anesthetized with pentobarbital and then decapitated. The temporal bone was removed. The otic capsule was opened and the cochlea was isolated by micro-dissection in a standard extracellular solution $\left(142 \mathrm{NaCl}, 5.37 \mathrm{KCl}, 1.47 \mathrm{MgCl}_{2}, 2 \mathrm{CaCl}_{2}, 10\right.$ HEPES in $\mathrm{mM}, 300 \mathrm{mOsm}, \mathrm{pH}$ 7.2). Brain tissue was also collected for a positive control. The experimental procedures were approved by the University of Kentucky's Animal Care \& Use Committee and conducted according to the standards of the NIH Guidelines for the Care and Use of Laboratory Animals.

Cross-sections of the cochlea were cut by cryosectioning (Liu and Zhao, 2008). The cochlea was fixed with $4 \%$ paraformaldehyde for $30 \mathrm{~min}$ and then decalcified in 10\% EGTA at room temperature with gentle agitation for 2-3 days, following infiltration with $30 \%$ glucose for 2 days (Hurley et al. 2003; Liu and Zhao, 2008). Then, the cochlea was embedded in OCT (Cat \# 4583, Sakura Finetek USA Inc. CA) at room temperature. The embedded cochlea was frozen at $-80^{\circ} \mathrm{C}$ overnight and cut $15-20 \mu \mathrm{m}$ thick at $-22 \sim 24{ }^{\circ} \mathrm{C}$ by a cryostat (Thermo Electron Corp. Waltham, MA). The tissue sections were directly mounted onto glass slides for staining and storage.

\section{Cochlear RNA extraction and RT-PCR performance}

As previously reported (Yu et al., 2008), the cochlea was freshly isolated and homogenized. Total RNA was extracted using Absolutely RNA Miniprep kit (Stratagen, La Jolla, CA) following the manufacturer's instructions, which included a DNase treatment to digest genomic DNA. The quality and quantity of mRNA was determined by a NanoDrop ND-1000 Spectrophotometer (NanoDrop Technologies, Inc., Rockland, DE). The obtained mRNA was converted to cDNA by iScript ${ }^{\mathrm{TM}} \mathrm{CDNA}$ Synthesis Kit (Bio-Rad, Hercules, CA). PCR amplification was conducted by MyiQ real-time PCR detection system with iQ SYBR Green Super Mix kit (Bio-Rad, Hercules, CA). The primers for pannexins are listed in Table 1. The PCR profile was as follows: $95^{\circ} \mathrm{C}$ for $45 \mathrm{~s}, 57^{\circ} \mathrm{C}$ (mouse) or $50.5^{\circ} \mathrm{C}$ (rat) for $1 \mathrm{~min}$, $72{ }^{\circ} \mathrm{C}$ for $60 \mathrm{~s}$, for 36 cycles. The brain cDNA served as a positive control. The amplified products were electrophoresized in a $1.7 \%$ agarose gel with ethidium bromide staining for visualization. The PCR products were also sequenced for verification.

\section{Antibodies and specificity}

The chicken anti-human Panx1 antibody (\#4515, a gift from Dr. Gerhard Dahl at the University of Miami Medical School) was used. This antibody is a polyclonal chicken IgG raised against amino acid residues EKNSRQRLLNPS in the human Panx1 C-terminus (Locovei et al, 2006b). The specificity of this anti-Panx 1 antibody was characterized in previous publications by Western blot and immunofluorescent staining in oocytes (Locovei et al, 2006b), Panx1 knockout mouse brain (Zoidl et al., 2007), and retina (Dvoriantchikova et al., 2006a). Single band at $\sim 43 \mathrm{kDa}$ was visible in the Western blot, and no specific band was observed in the Western blot of oocytes without injection of Panx1 mRNA (Locovei et al, 2006b) and Panx1 knockout mouse brain tissues (Zoidl et al., 2007). Specific, distinct distribution patterns of Panx1 expression in the brain and retina were also observed (Dvoriantchikova et al., 2006a; Zoidl et al., 2007) but were not seen in the knockout mouse (Zoidl et al., 2007).

The antibodies to Panx2 and Panx3 are polyclonal rabbit IgG. The rabbit anti-Panx2 antibody (Cat\# ARP42778_T100, Aviva System Biology, CA) was raised against a synthetic peptide (TPHNFTRDQALYA) corresponding to a region of human Panx2 and purified by protein A chromatography. The specificity of this antibody was verified by the manufacturer, showing a single band at $72 \mathrm{kDa}$ on the Western blot of HepG2 cell lysate and specific reaction in immunohistochemistry of skeletal muscle cells (Aviva manufacturer's technical information). In the present study, the specificity of this anti-Panx 2 antibody was 
further proved by a peptide-absorption assay (Supplementary Fig. 1), which the antibody was pre-incubated with the corresponding peptide antigen by $1(\mu \mathrm{g}): 1(\mu \mathrm{g})$ weight ratio (estimated molar ratio: 1: >100) at room temperature for $2 \mathrm{~h}$. This peptide pre-absorption completely eliminated the blotting band in the Western blot and labeling in the immunofluorescent staining (Supplementary Fig. 1).

The anti-Panx3 antibody (a gift from Dr. Dale Laird at the University of Western Ontario in Canada) was raised against a synthetic peptide derived from amino acid residues 379-392 (KPKHLTQHTYDEHA) in the C-terminus of mouse Panx3 (Penuela et al., 2007). The specificity of this antibody was verified by Western blot and peptide-absorption assay (Penuela et al., 2007). Single band was visible at $\sim 70 \mathrm{kDa}$ on the Western blot of lung, liver, spleen, and outer ear cartilage, and could be completely eliminated by peptide preabsorption. The specificity of this antibody was also further verified by probing for Panx3GFP proteins; the reactions to both Panx3 and GFP in Western blot and immunofluorescent labeling showed a positive correlation (Penuela et al., 2007).

The mouse monoclonal anti-Kir4.1 antibody (Cat\# H00003766-M01) was purchased from Novus Biologicals. This IgG2a Kappa antibody was raised against a KCNJ10 (NP_002232, 276 a.a. 380 a.a.) partial recombinant protein with GST tag (DFELVLILSGTVESTSATCQVRTSYLPEEILWGYEFTPAISLSASGKYIADFSLFDQ VVKVASPSGLRDSTVRYGDPEKLKLEESLREQAEKEGSALSVRISNV*), and was verified by recombinant proteins with GST tag on ELISA and Western blot (Novus manufacturer's technical information) and mouse cochlear tissues (Singh and Wangemann, 2008). The GST tag alone was used as a negative control. Single band was visible at 37.5 $\mathrm{kDa}$ in the blot. The rabbit anti-mouse Prestin antibody (a gift from Dr. Jing Zheng at the Northwestern University) is a polyclonal antibody raised against a synthetic oligopeptide derived from the C-terminus of mouse prestin (TASLPQEDMEPNATPTTPEA) (Matsuda et al., 2004). The specificity of the antibody to prestin was proved by Western blot and knockout mouse tissues. Only single band at $\sim 80 \mathrm{kDa}$ and oligomeric bands were visible in the Western blot of the cochlear tissues and no reaction was found in the Western blot and immunofluorescent staining of the prestin knockout mouse cochlea (Matsuda et al., 2004; Zheng et al., 2006; Yu et al., 2008).

\section{Pannexin Western blotting}

As previously reported (Yu et al., 2008), the whole cochlea and brain tissues were homogenized and lysed in the lysis buffer (10 mM Tris, $100 \mathrm{mM} \mathrm{NaCl}, 2 \mathrm{mM}$ EDTA, $0.1 \%$ SDS, $1 \%$ Triton X100) supplemented with phenylmethylsulfonyl fluoride (PMSF $100 \mu \mathrm{g} /$ $\mathrm{ml}$ ) and a protease inhibitor cocktail (1:50, P8340, Sigma-Aldrich, St. Louis MO). Tissue lysates were centrifuged at $3,000 \mathrm{~g}$, at $4^{\circ} \mathrm{C}$ for $5 \mathrm{~min}$. The supernatant was collected and boiled with Laemmli loading buffer (Bio-Rad, Hercules, CA) supplemented with $\beta$ mercaptoethanol $(0.7 \mathrm{mM})$ for $5 \mathrm{~min}$. Then, $50 \mu \mathrm{g}$ of protein per well was loaded onto the $10 \%$ SDS-polyAcrylamide gel. After electrophoresis, the gel proteins were electrotransferred onto an immuno-blot PVDF membrane. The membrane was blocked with $10 \%$ non-fat dry milk and 5\% fetal bovine serum, and incubated overnight at $4{ }^{\circ} \mathrm{C}$ with primary antibody to Panx1 (1:1,000, chicken anti-human Panx1), Panx2 (1:2,000, rabbit anti-human Panx2), or Panx3 (1:7,000, rabbit anti-mouse Panx3). After being washed with PBST (0.1M PBS, 0.1\% Tween-20), the membrane was incubated with HRP-conjugated goat anti-chicken or goat anti-rabbit antibody (1:2,000; Molecular Probes) in PBS with 10\% non-fat dry milk and 5\% fetal bovine serum. Finally, after being thoroughly washed with PBST, the membrane was developed with Enhanced Chemiluminescence (ECL) substrate (Pierce, Rockford, IL) for $2 \mathrm{~min}$. The ECL signal was exposed to X-ray film. The blots were scanned, digitalized, and analyzed by UN-SCAN-IT blotting analysis software (Silk Scientific Corp. Utah) (Yu et al., 2008). 
For re-probing for GAPDH in the peptide-absorption assay, the membrane was washed with PBST for 10 min two times, blocked with $10 \%$ non-fat dry milk and $5 \%$ fetal bovine serum for $1 \mathrm{~h}$ at room temperature, and re-blotted with mouse GAPDH monoclonal antibody (1:1,000, MMS-580S, Covance, CA) and goat anti-mousse secondary antibody following the immunoblotting detection procedure as described above (Yu et al., 2008).

\section{Pannexin immunofluorescent staining}

The immunofluorescent staining was performed as previously reported (Zhao and Yu, 2006; Yu et al., 2006; Liu and Zhao, 2008). After 30 min of incubation in a blocking solution (10\% goat serum and $1 \%$ BSA in PBS) with $0.1 \%$ Triton X-100, the tissue sections or isolated cells were incubated with anti-Panx1 (1: 400), anti-Panx2 (1:100), or anti-Panx3 (1:200) in the blocking solution at $4^{\circ} \mathrm{C}$ overnight. For double immunofluorescent staining for Panx 1 and prestin or Panx2 and Kir4.1, rabbit anti-prestin (1:500) or mouse monoclonal anti-Kir4.1 (1:200) was used for co-incubation. After being washed with PBS three times, the sections were incubated with corresponding Alexa Fluor 488- or 568-conjugated goat anti-chicken, goat anti-rabbit or goat anti-mouse secondary antibodies (1:400, Molecular Probes) for $2 \mathrm{hr}$ at room temperature $\left(23^{\circ} \mathrm{C}\right)$. In some cases, following the $2^{\text {nd }}$ antibody incubation, the sections or cells were stained by 4', 6-diamidino-2-phenylindole (DAPI, 0.1 $\mathrm{mg} / \mathrm{ml}$, D1306; Molecular Probes) for $\sim 15-20$ min to visualize cell nuclei. After completely washing out the second antibodies with PBS, the sections were mounted with a fluorescence mounting medium (H-1000, Vector Lab, CA) and observed under a confocal laser-scanning microscope. Hair cells that have no gap junctions were used as an internal negative control (see Fig. 4E\&F). We also omitted the primary antibodies in the experiment for negative control. No immunofluorescent labeling was observed.

\section{Confocal microscopy and image presentation}

The stained tissues or cells were observed under a Leica confocal microscope (Leica TCS SP2) excited by argon laser $(488 \mathrm{~nm})$ or krypton laser $(568 \mathrm{~nm})$. The DAPI nucleus staining was visualized by two-photon laser excitation with a $388-478 \mathrm{~nm}$ emission filter. The fluorescent image was saved in the TIFF format. Except as indicated in the legends, single confocal section was used and assembled in Photoshop (Adobe Systems, Mountain View, CA) for presentation.

\section{Results}

\section{Pannexin expression in the mammalian cochlea}

Pannexin expression in the cochlea was detected at the mRNA and protein levels by RTPCR and Western blotting, respectively (Figs. 1 and 2). The PCR amplification products of the mouse and rat cochlea for Panx1, Panx2, and Panx3 displayed bright bands, which had the same size as those in the positive controls of the brain samples (Fig. 1). The sequencing analysis of these PCR products showed the same sequences as the mouse and rat Panx1, Panx 2 and Panx3 (data not shown). It is noted that the band of Panx 3 in the mouse brain was relatively weak (Fig. 1A), consistent with previous reports that Panx3 was scarcely detectable in the mouse brain (Barbe et al., 2006; Penuela et al., 2007).

Expression of pannexins in the cochlea was also found in the Western blot (Fig. 2). Western blotting of the cochlear lysate for Panx 1 displayed a single intense band of $\sim 43 \mathrm{kDa}$ (the $1^{\text {st }}$ and $3^{\text {rd }}$ lanes in Fig. 2A) as the same as previously reported (Dvoriantchikova et al., 2006a; Penuela et al., 2007). In the positive control of the brain blots (the $2^{\text {nd }}$ and $4^{\text {th }}$ lanes in Fig. 2A), an additional minor band was also visible at $86 \mathrm{kDa}$, corresponding to the Panx 1 dimer size. Fig. 2B shows Western blotting for Panx2 in the cochlea and brain tissues. A single band was detected at $\sim 62 \mathrm{kD}$ in the brain Western blot, close to the previously 
reported size (Zappala et al., 2007). In the cochlear Western blot, a predominant oligomeric band of $\sim 110 \mathrm{kDa}$ was visible (the $1^{\text {st }}$ and $3^{\text {rd }}$ lanes in Fig. $2 \mathrm{~B}$ ). Both blotting bands could be blocked by pre-absorption of the corresponding peptide (Supplementary Fig. 1A). Western blot for Panx3 was also seen in two bands at $32 \mathrm{kDa}$ and $64 \mathrm{kDa}$ (Fig. 2C). The band of $64 \mathrm{kDa}$ was intense and only present in the cochlear blots (the $1^{\text {st }}$ and $3^{\text {rd }}$ lanes in Fig. 2C), whereas the band of $32 \mathrm{kDa}$ was minor and almost exclusively seen in the brain blots (the $2^{\text {nd }}$ and $4^{\text {th }}$ lanes in Fig. 2C).

\section{Distribution of Panx1 in the cochlea}

Immunofluorescent staining shows that Panx1 expression in the cochlea is predominant (Figs. 3 and 4). Intensive labeling for Panx1 was observed in the spiral limbus, the organ of Corti, the spiral prominence at the cochlear lateral wall, and the Reissner's membrane (Fig. 3). In the spiral limbus, the interdental cells had intense labeling (Figs. 3A\&B and 4A\&B). However, no labeling was found in the limbal fibrocytes below the interdental cells (Figs. 4A\&B). Positive labeling was also observed at the inner sulcus cells (Figs. 4A\&B). In the organ of Corti, Panx1 labeling was found in supporting cells, including pillar cells, Hensen cells, Boettcher cells, and Claudius cells (Figs. 3 and 4E-L). In the stack images (Figs. $3 \mathrm{E} \& \mathrm{~F})$, the labeling was strong and dense in the Claudius cells and Boettcher cells but weak and rare in the Deiters cells (Figs. 3C\&E). No labeling was found in the hair cells (Figs. $4 \mathrm{E} \& \mathrm{~F})$. In high-magnification images and in dissociated cell preparation, diffusecytoplasmic labeling was visible (Figs. 3C-F and 4), especially in the Claudius cells and Boettcher cells (Figs. 4I-L). Plaque-like punctate labeling was also detected between supporting cells and on the cell surface (indicated by solid and empty arrow-heads, respectively, in Fig. 4H and in the inset in Fig. 4J).

In the cochlear lateral wall, Panx1 labeling was observed in the outer sulcus cell (OSC) and in the spiral prominence (SP) and the central region in the spiral ligament (SPL) (Figs. $3 \mathrm{~A} \& \mathrm{~B}$ and $4 \mathrm{C} \& \mathrm{D})$. In the rat, positive labeling appeared in a dendritic-like pattern along the OSC root processes (Fig. 4C\&D). In the mouse, punctuate labeling showed a more uniform distribution in the SP and the central region in the SPL (Figs. 3A\&B, 6A). However, no labeling for Panx 1 was found in the upper region of the SPL (Figs. 3A\&B, 6A).

\section{Distributions of Panx2 and Panx3 in the cochlea}

Positive labeling for Panx2 was largely located in the cochlear lateral wall (Fig. 5A\&B). The labeling was located along the boundary between the stria vascularis (St.V) and SPL. In the high-magnification image, positive labeling for Panx2 was found to be located on the St.V side (Fig. 5C\&D). Kir4.1 in the cochlear lateral wall is only expressed in the strial intermediate cells and has been considered as an intermediate cell marker (Ando and Takeuchi, 1999; Singh and Wangemann, 2008). In double immunofluorescent staining with Kir4.1, Panx2 labeling was located at the outside of the positive Kir4.1 labeling cells and had no overlapping with Kir4.1 labeling (Fig. 5E\&F), indicating that Panx2 is expressed in the basal cells rather than in the intermediate cells in the St.V.

Fig. 6 shows double immunofluorescent labeling for Panx 1 and Panx 2 in the mouse cochlear lateral wall. Panx1 labeling was visible in the outer sulcus cells and type II fibrocytes in the central region, whereas Panx2 labeling was located in the basal cells in the St.V. No overlapping was observed. Panx1 labeling was also observed in the Reissner's membrane (Fig. 6B\&C). At the attachment site of the Reissner's membrane in the cochlear lateral wall, Panx1 labeling did not overlap with Panx2 labeling (Fig. 6B).

Immunofluorescent staining for Panx3 showed positive labeling in the bone at the cochlear lateral wall and the modiolus (Fig. 7A\&B). In the modiolus, the Panx3 labeling extended 
into the bottom of the spiral limbus along the bone but did not enter into the spiral limbus (Fig. 7C\&D).

\section{Pannexin expression in the spiral ganglion neurons and the strial blood vessels}

Panx1 labeling was also visible in blood vessel cells in the St.V (Fig. 8A\&B). In the wholemount preparation, the labeling showed a network along the blood vessels in the St.V (Fig. $8 \mathrm{C} \& \mathrm{D})$. We also found intense labeling for Panx2 in the spiral ganglion neurons. The labeling was located in the perinuclear region (Fig. 8E\&F).

\section{Discussion}

Our PCR and Western blotting results demonstrate the presence of pannexin expression in the inner ear. All three pannexin isoforms have been found in the cochlea (Figs. 1-2). As shown by immunofluorescent staining, Panx1 is a predominant isoform. Panx 1 expression was found in the interdental cells in the spiral limbus, the supporting cells in the organ of Corti, the inner and outer sulcus cells, and the type II fibrocytes in the spiral prominence and central region in the cochlear lateral wall (Figs. 3, 4 and 6). Panx1 labeling was also observed in the strial blood vessel cells (Fig. 8A-D). Panx2 expression was primarily located in the basal cells in the St.V (Figs. 5 and 6) and was also detected in the spiral ganglion neurons (Fig. 8E\&F). Panx3 labeling was only observed in the cochlear bone (Fig. 7). Thus, Panx1, Panx2 and Panx3 are all expressed in the mammalian cochlea and demonstrate distinct cellular distributions.

\section{Functional implication of pannexin expression in the cochlea}

Distinct distributions of Panx1, Panx2, and Panx3 in the cochlea imply that they can play diverse functions. Panx 1 expression was found in the supporting cells in the organ of Corti and at the spiral prominence in the cochlear lateral wall (Figs. 3, 4, and 6), located at both the epithelial gap junctional network and the connective tissue gap junctional network. Intense labeling for Panx1 was also observed at the Reissner's membrane (Figs. 3A\&B and $6 \mathrm{~B}$ ), which is thought to provide a size- and charge-selective barrier between endolymph and perilymph for maintaining their own unique fluid compositions (Wangemann and Schacht, 1996). Moreover, intense labeling for Panx1 was observed in the outer sulcus cells (Fig. 3 and 4). It has been reported that the outer sulcus cells participate in $\mathrm{K}^{+}$-transport and play an important role in regulating the endolymphatic $\mathrm{K}^{+}$concentration (Marcus and Chiba, 1999). Panx 1 labeling was also detected in the blood vessel cells in the St.V (Figs. 4,7), of which the endothelial barrier has been reported to be important for hearing (Cohen-Salmon et al., 2007). Therefore, these observations suggest that Panx1 may be particularly important for maintaining the inner ear homeostasis.

Panx2 has been found to be expressed in the strial basal cells (Figs. 5 and 6). In the cochlea, the St.V is responsible for the generation of the high positive endocochlear potential (EP, $+80 \mathrm{mV})$ and high potassium concentration $(155 \mathrm{mM})$ in the endolymph. Gap junctional coupling has been found to play a crucial role in the generation and maintenance of positive EP and high $\mathrm{K}^{+}$concentration (Couloigner et al., 2006; Wangemann, 2006). Panx2 in the basal cells may play a function similar to that of connexins in the EP generation. Panx 2 is also expressed in the spiral ganglion neurons (Fig. 8E\&F). It has been reported that Panx2 is co-localized with Panx1 in the neural system (Bruzzone et al., 2003; Vogt et al., 2005;Zappala et al., 2006,2007) and can form heterotypic channels with Panx1 (Bruzzone et al., 2003; Vogt et al., 2005). However, no overlapping labeling for Panx 1 and Panx2 was found in this study (Fig. 6). Panx3 expression was almost exclusively found in the cochlear bone (Fig. 7). This is consistent with a previous report that Panx3 is prevalently expressed in the bony structure (Penuela et al., 2007). 


\section{Subcellular expression of pannexins in the cochlea for gap junction and hemichannel formation and function}

In this study, we observed punctate labeling of Panx1 between the cochlear supporting cells (Fig. 4G-J). The punctate distribution of Panx1 expression has also been found in human epidermis (Penuela et al., 2007) and in tissue sections of retina and mouse lenses (Dvoriantchikova et al., 2006a, 2006b). However, the ability of pannexins to form intercellular gap junctional channels is still under debating. Panx1 proteins can assemble into intercellular gap junction channels in both homomeric and heteromeric configurations in Xenopus oocytes (Bruzzone et al., 2003; Bao et al., 2004) and in the C6 glioma cell line (Lai et al., 2007). It has also been reported that Panx 1 is capable of forming $\mathrm{Ca}^{++}$-permeable intercellular channels (Vanden Abeele et al., 2006; Peters et al., 2007). However, Panx1expressed HeLa cells and N2A cells lack dye transfer and electrical coupling (Boassa et al., 2007; Huang Y et al., 2007).

In contrast to contrary findings of the formation of gap junctional channels, considerable evidence supports the concept that pannexins can form functional hemichannels (Bruzzone et al. 2003, 2005; Bao et al., 2004; Locovei et al., 2006a, 2006b; Huang YJ et al., 2007; Lai et al., 2007). The activity of pannexin hemichannels was detected even in connexin-deficient erythrocytes (Locovei et al., 2006b). Like connexons (connexin hemichannels), pannexin hemichannels are also mechanosensitive and can release ATP (Bao et al., 2004; Locovei et al., 2006a, 2006b; Huang YJ et al., 2007). Hemichannel-mediated ATP release has been reported to play an important role in the control of hearing (Zhao et al., 2005). Hemichannels can also mediate inositol 1,4,5-trisphosphate $\left(\mathrm{IP}_{3}\right)$ release to participate in intercellular signaling in the cochlea (Gossman and Zhao, 2008). In this study, Panx 1 labeling on the cochlear supporting cell surface was detected (Figs. 3 and 4). Pannexin may also play an important role in the cochlea for hearing controlling and intercellular signaling.

\section{Connexin and pannexin mutation induced hearing loss}

It has been well demonstrated that connexin mutations can induce hearing loss (Kelsell et al., 1997; Zhao et al., 2006). Pannexins are the new identified gene family and also encode gap junctions in mammals. Genomics analysis shows that Panx1 is located on human chromosome 11q14.3 in a $700 \mathrm{~kb}$ interval between the genes CRSP6 and MRE11, Panx2 on human chromosome 22q13.31 - q13.33, and Panx3 on human chromosome 11q24.2 (Baranova et al., 2004). It has been reported that the region of nonsyndromic sensorineural deafness DFNA11 loci maps to chromosome 11q12.3 - q21 (Tamagawa et al., 1996), which overlaps with the Panx1 gene location. However, no pannexin mutation-induced hearing loss has been identified yet. Currently, it is unclear whether pannexin mutations can induce hearing loss. The physiologic function of pannexins in the cochlea also remains undetermined. This requires further studies in future.

The present study shows for the first time the expression of pannexins in the mammalian cochlea. Each pannexin isoform demonstrates a distinct distribution. This implies that like connexins pannexins may also play an important role in the cochlea for hearing.

\section{Acknowledgments}

We are grateful to Dr. Gerhard Dahl at Miami University and Dr. Dale Laird at University of Western Ontario, Canada, for kindly providing anti-Panx 1 and 3 antibodies respectively. This work was supported by a grant (R01) from the National Institute on Deafness and Other Communication Disorders DC 05989 


\section{References}

Ando M, Takeuchi S. Immunological identification of an inward rectifier $\mathrm{K}^{+}$channel (Kir4.1) in the intermediate cell (melanocyte) of the cochlear stria vascularis of gerbils and rats. Cell Tissue Res. 1999; 298:179-183. [PubMed: 10555552]

Bao L, Locovei S, Dahl G. Pannexin membrane channels are mechanosensitive conduits for ATP. FEBS Lett. 2004; 572:65-68. [PubMed: 15304325]

Baranova A, Ivanov D, Petrash N, Pestova A, Skoblov M, Kelmanson I, Shagin D, Nazarenko S, Geraymovych E, Litvin O, Tiunova A, Born TL, Usman N, Staroverov D, Lukyanov S, Panchin Y. The mammalian pannexin family is homologous to the invertebrate innexin gap junction proteins. Genomics. 2004; 83:706-716. [PubMed: 15028292]

Barbe MT, Monyer H, Bruzzone R. Cell-cell communication beyond connexins: the pannexin channels. Physiology (Bethesda). 2006; 21:103-114. [PubMed: 16565476]

Boassa D, Ambrosi C, Qiu F, Dahl G, Gaietta G, Sosinsky G. Pannexin1 channels contain a glycosylation site that targets the hexamer to the plasma membrane. J Biol Chem. 2007; 282:3173331743. [PubMed: 17715132]

Bruzzone R, Hormuzdi SG, Barbe MT, Herb A, Monyer H. Pannexins, a family of gap junction proteins expressed in brain. Proc Natl Acad Sci USA. 2003; 100:13644-13649. [PubMed: 14597722]

Bruzzone R, Barbe MT, Jakob NJ, Monyer H. Pharmacological properties of homomeric and heteromeric pannexin hemichannels expressed in Xenopus oocytes. J Neurochem. 2005; 92:10331043. [PubMed: 15715654]

Couloigner V, Sterkers O, Ferrary E. What's new in ion transports in the cochlea? Pflugers Arch. 2006; 453:11-22. [PubMed: 16773381]

Cohen-Salmon M, Regnault B, Cayet N, Caille D, Demuth K, Hardelin JP, Janel N, Meda P, Petit C. Connexin30 deficiency causes instrastrial fluid-blood barrier disruption within the cochlear stria vascularis. Proc Natl Acad Sci USA. 2007; 104:6229-6234. [PubMed: 17400755]

Dvoriantchikova G, Ivanov D, Panchin Y, Shestopalov VI. Expression of pannexin family of proteins in the retina. FEBS Lett. 2006a; 580:2178-2182. [PubMed: 16616526]

Dvoriantchikova G, Ivanov D, Pestova A, Shestopalov V. Molecular characterization of pannexins in the lens. Mol Vis. 2006b; 12:1417-1426. [PubMed: 17149368]

Forge A, Becker D, Casalotti S, Edwards J, Evans WH, Lench N, Souter M. Gap junctions and connexin expression in the inner ear. Novartis Found Symp. 1999; 219:134-150. discussion 151-163. [PubMed: 10207902]

Forge A, Becker D, Casalotti S, Edwards J, Marziano N, Nevill G. Gap junctions in the inner ear: comparison of distribution patterns in different vertebrates and assessement of connexin composition in mammals. J Comp Neurol. 2003; 467:207-231. [PubMed: 14595769]

Gossman DG, Zhao HB. Hemichannel-mediated inositol 1,4,5 - trisphosphate (IP3) release in the cochlea: A novel mechanism of IP3 intercellular signaling. Cell Commun Adhes. 2008; 15:305315. [PubMed: 18979296]

Harris AL. Emerging issues of connexin channels: biophysics fills the gap. Q Rev Biophys. 2001; 34:325-472. [PubMed: 11838236]

Huang Y, Grinspan JB, Abrams CK, Scherer SS. Pannexin1 is expressed by neurons and glia but does not form functional gap junctions. Glia. 2007; 55:46-56. [PubMed: 17009242]

Huang YJ, Maruyama Y, Dvoryanchikov G, Pereira E, Chaudhari N, Roper SD. The role of pannexin 1 hemichannels in ATP release and cell-cell communication in mouse taste buds. Proc Natl Acad Sci USA. 2007; 104:6436-6441. [PubMed: 17389364]

Hurley PA, Clarke M, Crook JM, Wise AK, Shepherd RK. Cochlear immunochemistry - a new technique based on gelatin embedding. J Neurosci Methods. 2003; 129:81-86. [PubMed: 12951235]

Kelsell DP, Dunlop J, Stevens HP, Lench NJ, Liang JN, Parry G, Mueller RF, Leigh IM. Connexin 26 mutations in hereditary nonsyndromic sensorineural deafness. Nature. 1997; 387:80-83. [PubMed: 9139825] 
Kikuchi T, Kimura RS, Paul DL, Adams JC. Gap junctions in the rat cochlea: immunohistochemical and ultrastructural analysis. Anat Embryol. 1995; 191:101-118. [PubMed: 7726389]

Lai CP, Bechberger JF, Thompson RJ, MacVicar BA, Bruzzone R, Naus CC. Tumor-suppressive effects of pannexin 1 in C6 glioma cells. Cancer Res. 2007; 67:1545-1554. [PubMed: 17308093]

Liu YP, Zhao HB. Cellular characterization of Connexin26 and Connnexin30 expression in the cochlear lateral wall. Cell Tissue Res. 2008; 333:395-403. [PubMed: 18581144]

Locovei S, Wang J, Dahl G. Activation of pannexin 1 channels by ATP through P2Y receptors and by cytoplasmic calcium. FEBS Lett. 2006a; 580:239-244. [PubMed: 16364313]

Locovei S, Bao L, Dahl G. Pannexin 1 in erythrocytes: function without a gap. Proc Natl Acad Sci USA. 2006b; 103:7655-7659. [PubMed: 16682648]

Marcus DC, Chiba T. $\mathrm{K}^{+}$and $\mathrm{Na}^{+}$absorption by outer sulcus epithelial cells. Hear Res. 1999; 134:4856. [PubMed: 10452375]

Matsuda K, Zheng J, Du GG, Klocker N, Madison LD, Dallos P. N-linked glycosylation sites of the motor protein prestin: Effects on membrane targeting and electrophysiological function. J Neurochem. 2004; 89:928-938. [PubMed: 15140192]

Panchin Y, Kelmanson I, Matz M, Lukyanov K, Usman N, Lukyanov S. A ubiquitous family of putative gap junction molecules. Curr Biol. 2000; 10:R473-474. [PubMed: 10898987]

Pelegrin P, Surprenant A. Pannexin-1 couples to maitotoxin- and nigericin-induced interleukin-1beta release through a dye uptake-independent pathway. J Biol Chem. 2007; 282:2386-2394. [PubMed: 17121814]

Peters MA, Teramoto T, White JQ, Iwasaki K, Jorgensen EM. A calcium wave mediated by gap junctions coordinates a rhythmic behavior in C.elegans. Curr Biol. 2007; 17:1601-1608. [PubMed: 17825560]

Penuela S, Bhalla R, Gong XQ, Cowan KN, Celetti SJ, Cowan BJ, Bai D, Shao Q, Laird DW. Pannexin 1 and pannexin 3 are glycoproteins that exhibit many distinct characteristics from the connexin family of gap junction proteins. J Cell Sci. 2007; 120:3772-3783. [PubMed: 17925379]

Ray A, Zoidl G, Weickert S, Wahle P, Dermietzel R. Site-specific and developmental expression of pannexin1 in the mouse nervous system. Eur J Neurosci. 2005; 21:3277-3290. [PubMed: 16026466]

Ray A, Zoidl G, Wahle P, Dermietzel R. Pannexin expression in the cerebellum. Cerebellum. 2006; 5:189-192. [PubMed: 16997749]

Shestopalov VI, Panchin Y. Pannexins and gap junction protein diversity. Cell Mol Life Sci. 2008; 65:376-394. [PubMed: 17982731]

Singh R, Wangemann P. Free radical stress-mediated loss of Kcnj10 protein expression in stria vascularis contributes to deafness in Pendred syndrome mouse model. Am J Physiol Renal Physiol. 2008; 294:F139-148. [PubMed: 17959752]

Tamagawa Y, Kitamura K, Ishida T, Ishikawa K, Tanaka H, Tsuji S, Nishizawa M. A gene for a dominant form of non-syndromic sensorineural deafness (DFNA11) maps within the region containing the DFNB2 recessive deafness gene. Hum Mol Genet. 1996; 5:849-852. [PubMed: 8776602]

Vanden Abeele F, Bidaux G, Gordienko D, Beck B, Panchin YV, Baranova AV, Ivanov DV, Skryma R, Prevarskaya N. Functional implications of calcium permeability of the channel formed by pannexin1. J Cell Biol. 2006; 174:535-546. [PubMed: 16908669]

Vogt A, Hormuzdi SG, Monyer H. Pannexin1 and Pannexin2 expression in the developing and mature rat brain. Brain Res Mol Brain Res. 2005; 141:113-120. [PubMed: 16143426]

Wang, XH.; Streeter, M.; Zhao, HB. Pannexin expression in the cochlea of mammals: An alternative gap junction; The 112th American Academy of Otolaryngology - Head \& Neck Surgery Annual Meeting; Chicago, IL. 2008.

Wangemann, P.; Schacht, J. Homeostatic mechanisms in the cochlea. In: Dallos, P.; Popper, AN.; Fay, RR., editors. The Cochlea. Springer-Verlag; New York: 1996. p. 130-185.

Wangemann P. Supporting sensory transduction: cochlear fluid homeostasis and the endocochlear potential. J Physiol. 2006; 576:11-21. [PubMed: 16857713] 
Weickert S, Ray A, Zoidl G, Dermietzel R. Expression of neural connexins and pannexin1 in the hippocampus and inferior olive: a quantitative approach. Brain Res Mol Brain Res. 2005; 133:102-109. [PubMed: 15661370]

Willecke K, Eiberger J, Degen J, Eckardt D, Romualdi A, Guldenagel M, Deutsch U, Sohl G. Structural and functional diversity of connexin genes in the mouse and human genome. Biol Chem. 2002; 383:725-737. [PubMed: 12108537]

Yu N, Zhu ML, Zhao HB. Prestin is expressed on the whole outer hair cell basolateral surface. Brain Res. 2006; 1095:51-58. [PubMed: 16709400]

Yu N, Zhu ML, Johnson B, Liu YP, Jones RO, Zhao HB. Prestin up-regulation in chronic salicylate (aspirin) administration: An implication of functional dependence of prestin expression. Cell Mol Life Sci. 2008; 65:2407-2418. [PubMed: 18560754]

Zappalà A, Cicero D, Serapide MF, Paz C, Catania MV, Falchi M, Parenti R, Pantò MR, La Delia F, Cicirata F. Expression of pannexin1 in the CNS of adult mouse: cellular localization and effect of 4-aminopyridine-induced seizures. Neuroscience. 2006; 141:167-178. [PubMed: 16690210]

Zappalà A, Li Volti G, Serapide MF, Pellitteri R, Falchi M, La Delia F, Cicirata V, Cicirata F. Expression of pannexin2 protein in healthy and ischemized brain of adult rats. Neuroscience. 2007; 148:653-667. [PubMed: 17692470]

Zhao HB. Directional rectification of gap junctional voltage gating between Deiters cells in the inner ear of guinea pig. Neurosci Lett. 2000; 296:105-108. [PubMed: 11108992]

Zhao, HB. Biophysical properties and functional analysis of inner ear gap junctions for deafness mechanisms of nonsyndromic hearing loss; Proceedings of the $9^{\text {th }}$ International Meeting on Gap Junctions; Cambridge, United Kingdom. August 23-28; 2003.

Zhao HB, Kikuchi T, Ngezahayo A, White TW. Gap junctions and cochlear homeostasis. J Memb Biol. 2006; 209:177-186.

Zhao HB, Santos-Sacchi J. Auditory collusion and a coupled couple of outer hair cells. Nature. 1999; 399:359-362. [PubMed: 10360573]

Zhao HB, Santos-Sacchi J. Voltage gating of gap junctions in cochlear supporting cells: evidence for nonhomotypic channels. J Memb Biol. 2000; 175:17-24.

Zhao HB, Yu N. Distinct and gradient distributions of connexin26 and connexin30 in the cochlear sensory epithelium of guinea pigs. J Comp Neurol. 2006; 499:506-518. [PubMed: 16998915]

Zhao HB, Yu N, Fleming CR. Gap junctional hemichannel-mediated ATP release and hearing controls in the inner ear. Proc Natl Acad Sci USA. 2005; 102:18724-18729. [PubMed: 16344488]

Zheng J, Du GG, Anderson CT, Keller JP, Orem A, Dallos P, Cheatham M. Analysis of the oligomeric structure of the motor protein prestin. J Biol Chem. 2006; 281:19916-19924. [PubMed: 16682411]

Zoidl G, Petrasch-Parwez E, Ray A, Meier C, Bunse S, Habbes HW, Dahl G, Dermietzel R. Localization of the pannexin 1 protein at postsynaptic sites in the cerebral cortex and hippocampus. Neuroscience. 2007; 146:9-16. [PubMed: 17379420] 


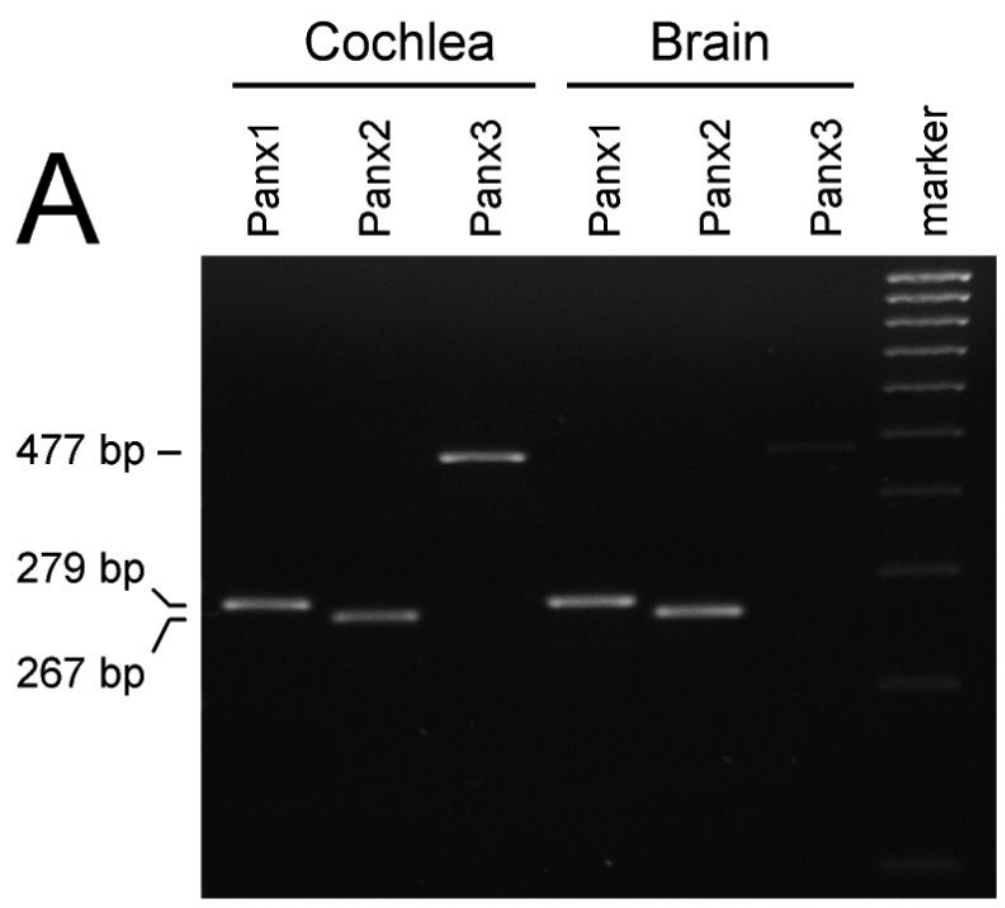

\section{Mouse}

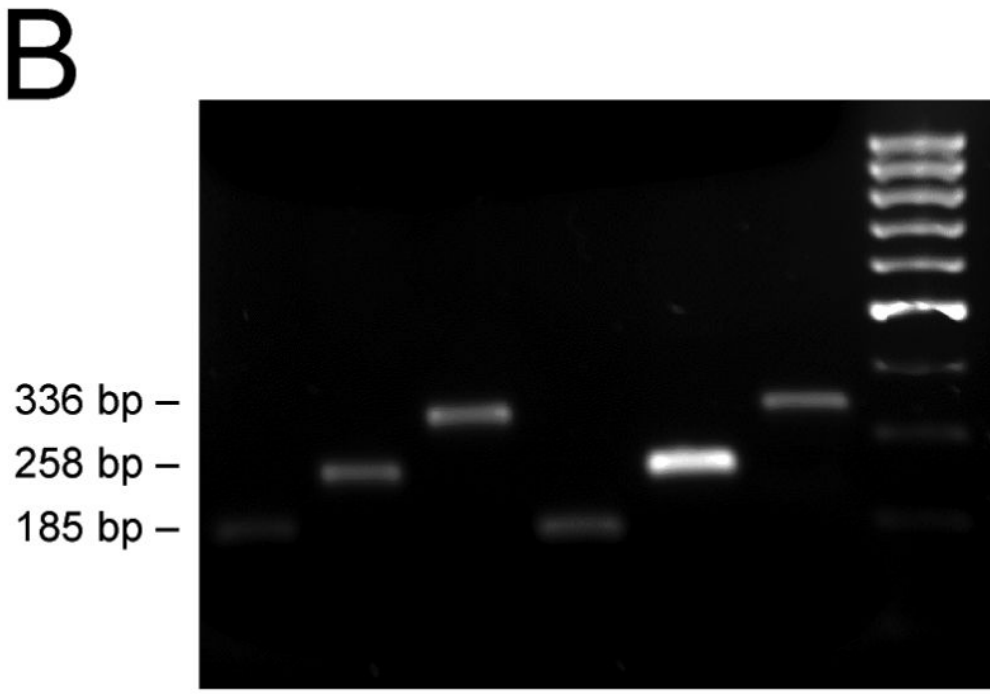

\section{Rat}

Figure 1.

Detection of pannexin expression in the mouse and rat cochlea by RT-PCR examination. A: The PCR amplification of the mouse cochlea and brain for Panx1, 2, and 3. The expected lengths of 279, 269, and $477 \mathrm{bp}$ for Panx1, 2, and 3, respectively, were obtained in both cochlea and brain PCR products. B: The PCR amplification of Panx1, 2, and 3 in the rat cochlea and brain. The lengths of both cochlear and brain PCR products were 185, 258, and 336 bp for Panx1, 2, and 3, respectively. 


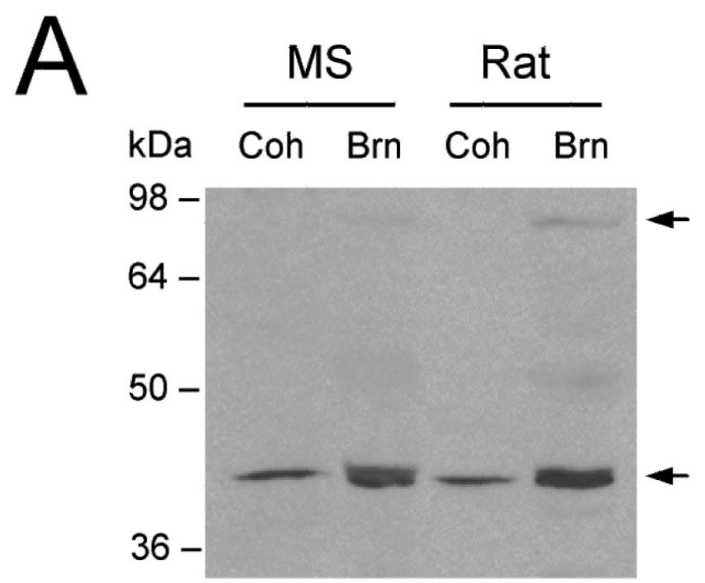

B

Anti-Panx1

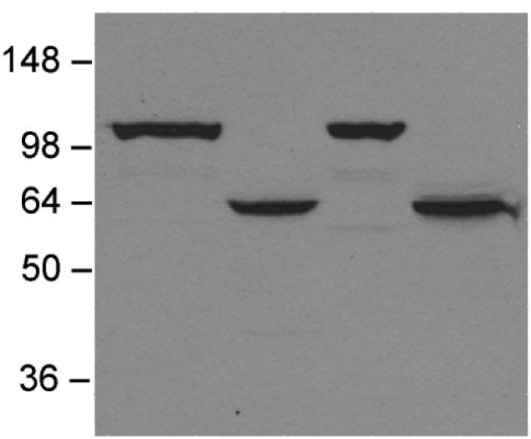

Anti-Panx2
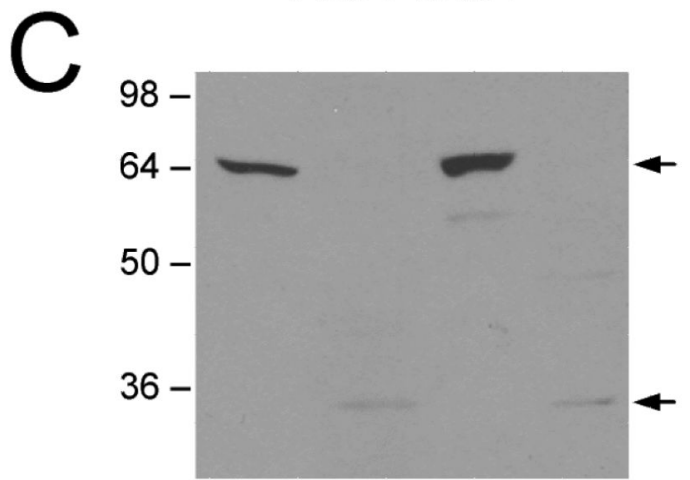

Anti-Panx3

Figure 2.

Western blots of Panx 1, 2, and 3 proteins in the cochlea and brain. A: Western blots of Panx 1 in the cochlear and brain tissues of mice and rats. The blot of the cochlear lysate shows a single band corresponding to $43 \mathrm{kDa}$, while the blotting of the brain tissue demonstrates multimeric bands at $43 \mathrm{kDa}$ and $86 \mathrm{kDa}$ (indicated by arrows). B: Western blot of Panx2 in the cochlear and brain tissues. C: Western blot of the cochlear and brain tissues for Panx3. Arrows indicate Panx3 bands at $32 \mathrm{kDa}$ and $64 \mathrm{kDa}$, respectively. 

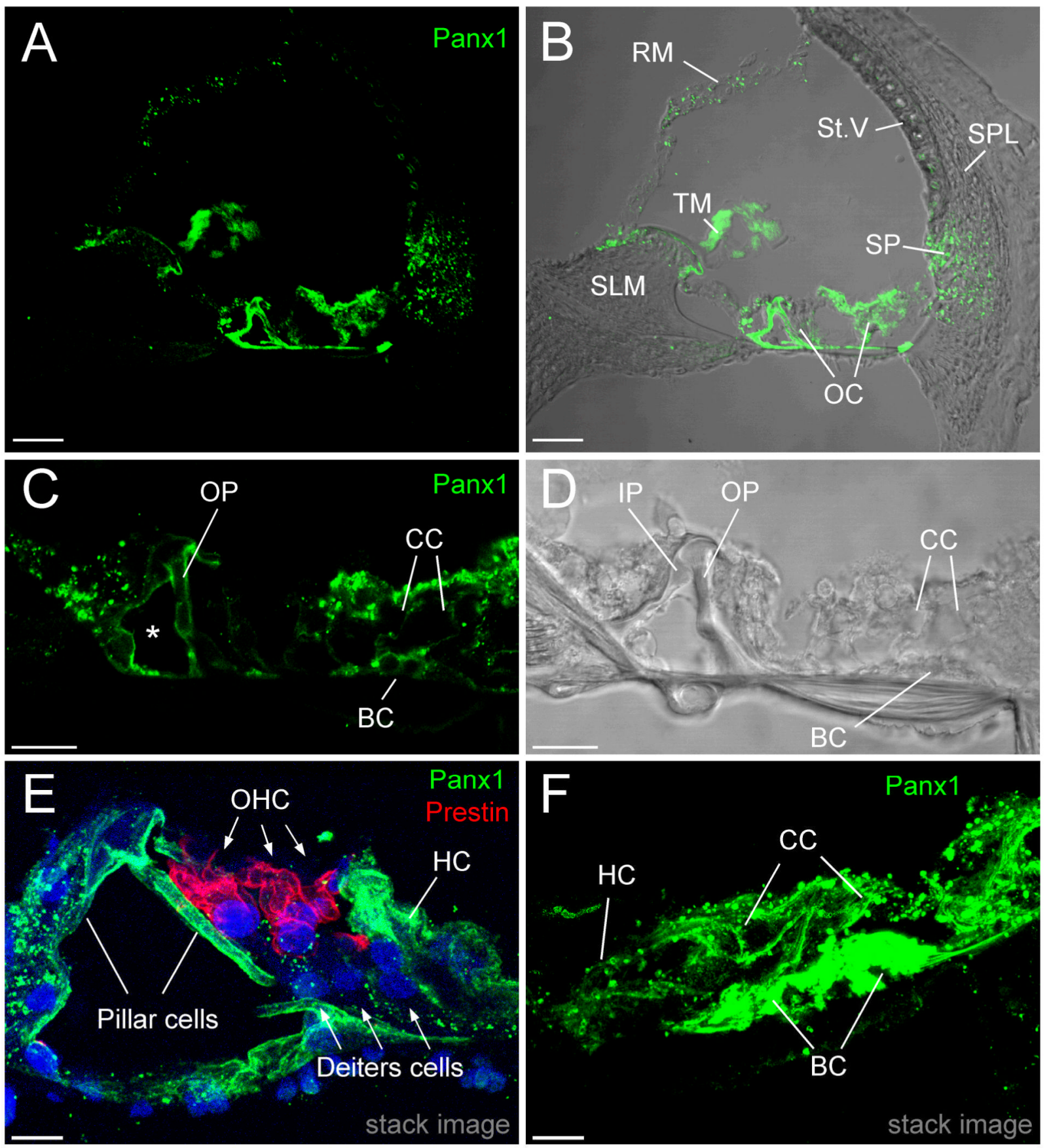

Figure 3.

Immunofluorescent staining for Panx 1 in the cochlea. A\&B: Panx 1 labeling in the crosssection of the mouse cochlea. Panel A is an immunofluorescent image. Positive labeling is visible in the spiral prominence, the organ of Corti, the spiral limbus, and the Reissner's membrane. C\&D: High-magnification images of Panx1 labeling in the mouse organ of Corti. A star indicates the tunnel. E\&F: High-magnification images of Panx1 labeling in the rat cochlea. The section was double-stained for Panx1 (green) and prestin (red). The images were stacked from serial confocal scanning sections. Intense labeling is visible in Claudius cells and Boettcher cells. RM: Reissner's membrane, TM: tectorial membrane, St.V: stria vascularis, SPL: spiral ligament, SP: spiral prominence, OC: organ of Corti, SLM: spiral 
limbus. OHC: outer hair cell, HC: Hensen cell, CC: Claudius cell, BC: Boettcher cell. Scale bars: $50 \mu \mathrm{m}$ in $\mathrm{A} \& \mathrm{~B} ; 20 \mu \mathrm{m}$ in $\mathrm{C} \& \mathrm{D} ; 10 \mu \mathrm{m}$ in $\mathrm{E} \& \mathrm{~F}$. 


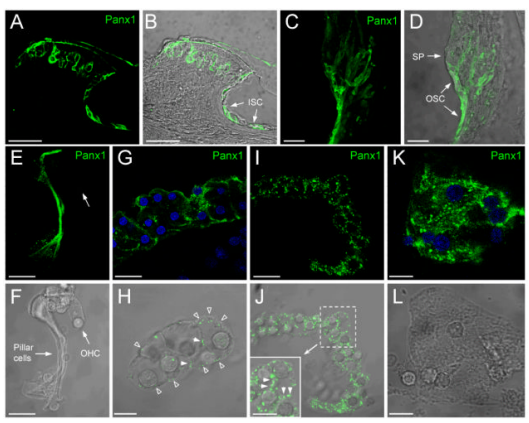

\section{Figure 4.}

Immunofluorescent labeling for Panx1 in the rat cochlea. A-D: High magnification images of immunofluorescent staining for Panx1 in the spiral limbus (panel A, B) and the spiral prominence (SP) in the cochlear lateral wall (panel C, D) in the cochlear cross-section. Arrows in panel B indicate the inner sulcus cells (ISC). Intense labeling is also visible in the outer sulcus cells (OSC) and their root processes (panel C, D). E-L: Immunofluorescent staining for Panx1 in the pillar cells (panel E, F), Hensen cells (panel G, H), Claudius cells (panel I, J), and Boettcher cells (panel K, L) in the dissociated cell preparation. White arrows in panels E\&F indicate an outer hair cell $(\mathrm{OHC})$ that has no fluorescence labeling. In the panel H, solid and empty arrow heads indicate punctate labeling between Hensen cells and on the cell surface, respectively. Panels I\&J are immunofluorescent staining of a piece of Claudius cells for Panx1. Inset: high magnification view of the dashed line box in panel J. Arrow heads indicate punctate labeling between cells. Scale bars: $40 \mu \mathrm{m}$ in A\&B; $25 \mu \mathrm{m}$ in $\mathrm{C} \& \mathrm{D} ; 20 \mu \mathrm{m}$ in $\mathrm{E}-\mathrm{G}, \mathrm{I}$, and $\mathrm{J} ; 10 \mu \mathrm{m}$ in $\mathrm{H}, \mathrm{K}, \mathrm{L}$, and an inset in $\mathrm{J}$. 

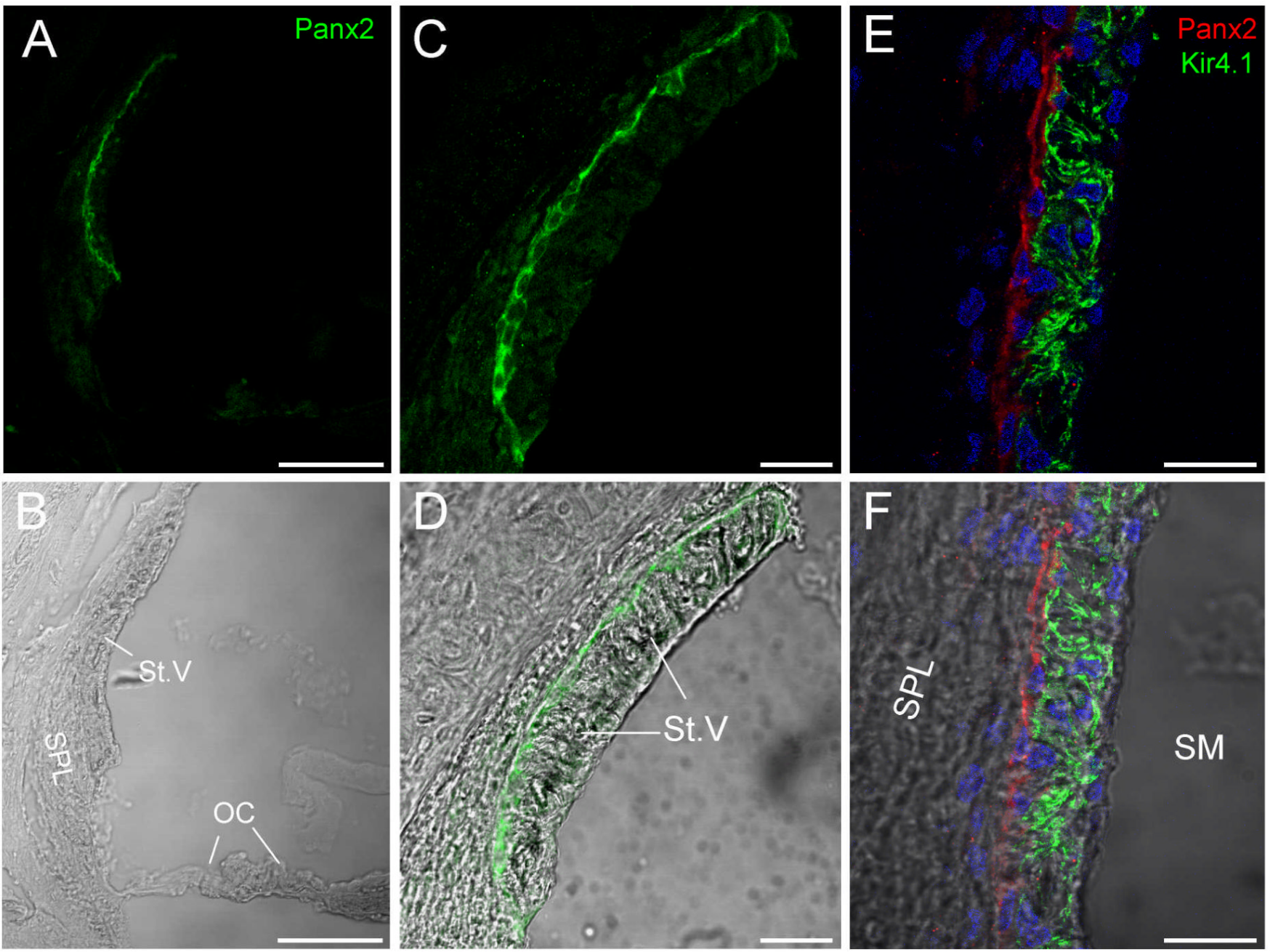

Figure 5.

Immunofluorescent staining for Panx2 in the cochlea. A\&B: Panx2 labeling in the crosssection of the rat cochlea. Positive labeling is visible along the boundary between the stria vascularis (St.V) and the spiral ligament (SPL). OC: organ of Corti. C\&D: Highmagnification images of Panx2 labeling in the mouse cochlear lateral wall. E\&F: Double immunofluorescent staining for Panx2 (red) and Kir4.1 (green) in the cochlear lateral wall. The cell nuclei were stained in blue color by DAPI. SM: scala media. Scale bars: $100 \mu \mathrm{m}$ in $\mathrm{A} \& \mathrm{~B} ; 25 \mu \mathrm{m}$ in $\mathrm{C} \& \mathrm{D} ; 20 \mu \mathrm{m}$ in $\mathrm{E} \& \mathrm{~F}$. 


\section{A}

Panx1 Panx2
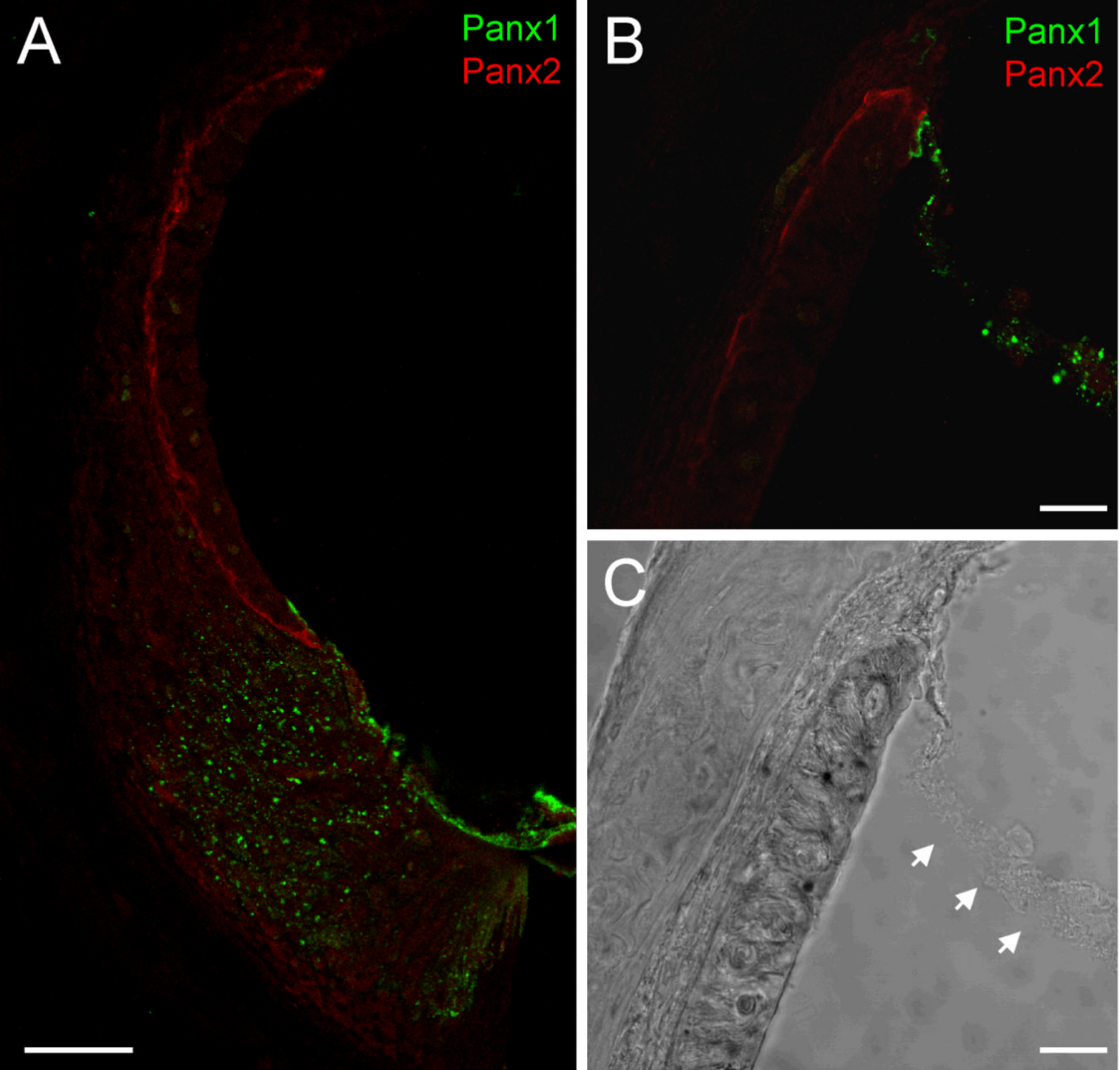

Figure 6.

A: Double immunofluorescent staining for Panx1 and Panx2 in the mouse cochlear lateral wall. Green and red colors represent labeling for Panx1 and Panx2, respectively. No overlay labeling is visible. B\&C: High magnification view of double immunofluorescent labeling for Panx1 (green) and Panx2 (red) in the Reissner's membrane and the St.V. No overlapping staining is visible at the attachment site of the Reissner's membrane. White arrows in panel $\mathrm{C}$ indicate the Reissner's membrane. Scale bars: $50 \mu \mathrm{m}$ in A; $20 \mu \mathrm{m}$ in B\&C. 


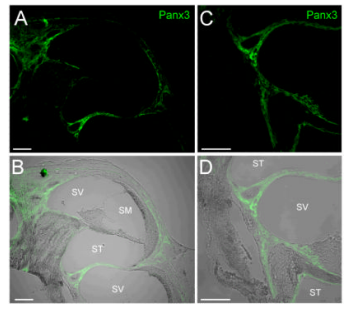

Figure 7.

Immunofluorescent staining for Panx3 in the cochlea. A\&B: Panx3 labeling in the mouse cochlea. Positive labeling for Panx3 is visible in the bone at the cochlear lateral wall and modiolus. SV: scala vestibuli; SM: scala media; ST: scala tympani. C\&D: High-

magnification images of Panx3 labeling in the modiolus. Scale bars: $100 \mu \mathrm{m}$. 

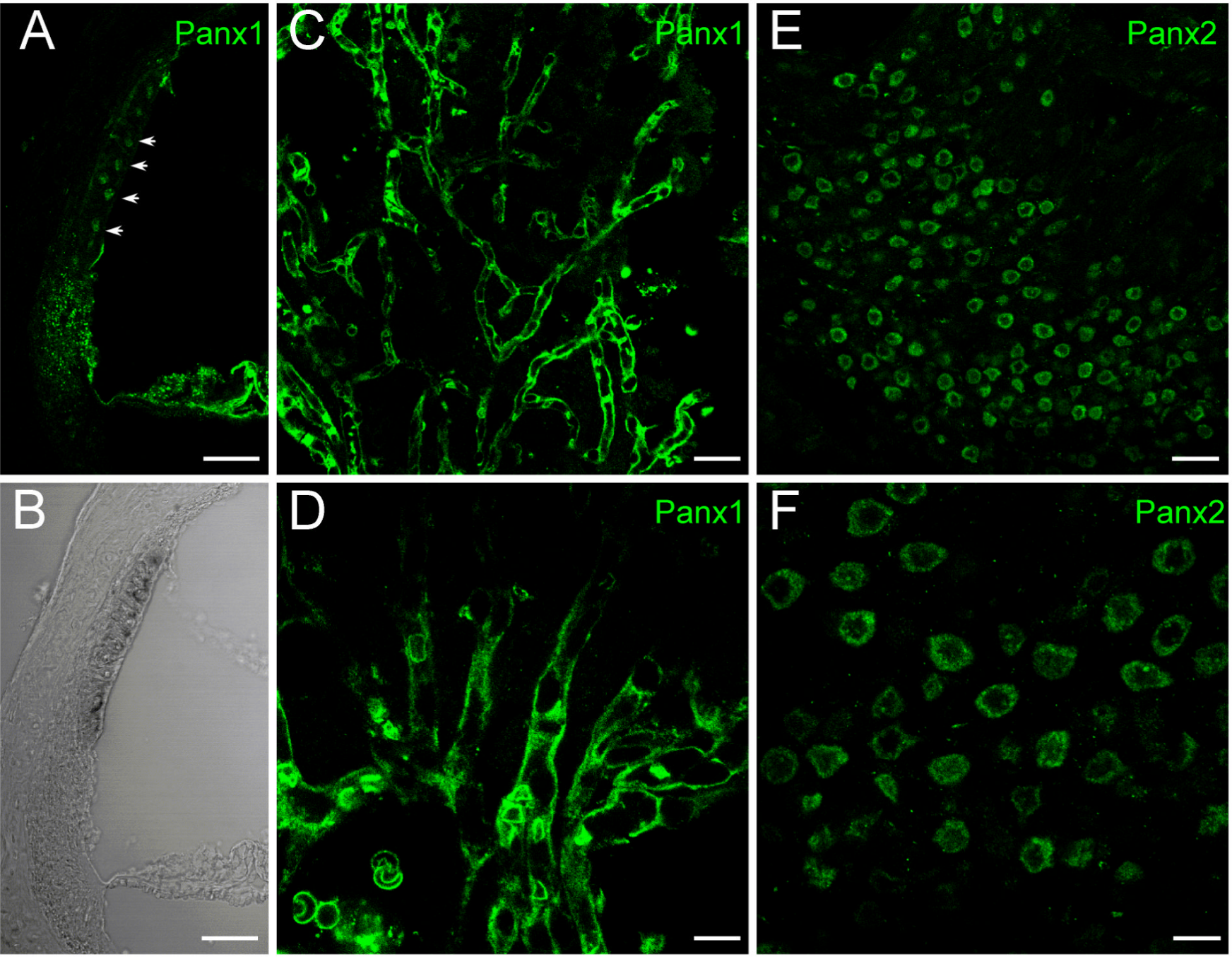

Figure 8.

Pannexin expression in the strial blood vessel cells and the spiral ganglion neurons. A\&B: The mouse cochlear cross-section. Arrows indicate positive labeling for Panx1 in the blood vessel cells in the St.V. C\&D: Panx1 labeling in the strial blood vessel cells in wholemounting preparation. Panel D is a high-magnification image. E\&F: Positive labeling for Panx2 in the rat spiral ganglion neurons. Scale bars: $50 \mu \mathrm{m}$ in A\&B; $25 \mu \mathrm{m}$ in C\&E; $10 \mu \mathrm{m}$ in $\mathrm{D} \& \mathrm{~F}$. 
Table 1

PCR Primers

\begin{tabular}{|c|c|c|c|}
\hline Name & Species & Sense/Antisense primers & Predicated Size (bp) \\
\hline \multirow[t]{2}{*}{$\operatorname{Panx} 1^{a}$} & Mouse & $5^{\prime}$ - CAA GGG AGA GGA CCA GGG C - 3' & 279 \\
\hline & & $5^{\prime}-$ ATC TAT TCT TCT ATG ACG CTG - $3^{\prime}$ & \\
\hline \multirow[t]{2}{*}{$\operatorname{Panx} 2^{b}$} & Mouse & $5^{\prime}$ - GAG AAA AAG CAT ACC CGC CAC - 3' & 267 \\
\hline & & $5^{\prime}$ - GGG TGA GCA GAC ATG GAA TGA - 3' & \\
\hline \multirow[t]{2}{*}{ Panx3 } & Mouse & $5^{\prime}$ - CCT CAC AAG GCT CTT CCC TA - 3' & 477 \\
\hline & & $5^{\prime}$ - AGG TCA GCC TGC ATG TGA TC - 3' & \\
\hline \multirow[t]{2}{*}{$\operatorname{Panx} 1^{c}$} & Rat & 5' - TTC TTC CCC TAC ATC CTG CT - 3' & 185 \\
\hline & & 5' - GGT CCA TCT CTC AGG TCC AA - 3' & \\
\hline \multirow[t]{2}{*}{$\operatorname{Panx} 2^{c}$} & Rat & $5^{\prime}$ - TGG ACA TCG TAT TGC TCT GC - 3' & 258 \\
\hline & & $5^{\prime}$ - CCA CGT TGT CGT ACA TGA GG - 3' & \\
\hline \multirow[t]{2}{*}{$\operatorname{Pan} \times 3^{c}$} & Rat & $5^{\prime}$ - GAC CCC CTG AAA CAC TTT GA - $3^{\prime}$ & 336 \\
\hline & & $5^{\prime}-$ TCT AAC CCA CTG GCC TTC AC - $3^{\prime}$ & \\
\hline
\end{tabular}

${ }^{a}$ Dvoriantchikova et al., 2006.

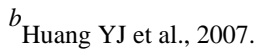

${ }^{c}$ Lai et al., 2007. 